\title{
PULLOUT BEHAVIOR OF STEEL FIBERS IN SELF-COMPACTING CONCRETE
}

\author{
Vítor M. C. F. Cunha ${ }^{1}$, Joaquim A. O. Barros ${ }^{2}$ and José M. Sena-Cruz ${ }^{3}$
}

\begin{abstract}
In steel fiber reinforced composites materials, fiber and matrix are bonded together through a weak interface. The study of this interfacial behavior is important for understanding the mechanical behavior of such composites. Moreover, with the outcome of new composites materials with improved mechanical properties and advanced cement matrices, such in the case of steel fiber reinforced self-compacting concrete, the study of the fiber/matrix interface assumes a new interest. In the present work, experimental results of both straight and hooked end steel fibers pullout tests on a self-compacting concrete medium are presented and discussed. Emphasis is given to the accurate acquirement of the pullout load versus endslip relationship. The influence of fiber embedded length and orientation on the fiber pullout behavior is studied. Additionally, the separate assessment of the distinct bond mechanisms is performed, by isolating the adherence bond from the mechanical bond provided by the hook. Finally, analytical bond-slip relationships are obtained by back-analysis procedure with an interfacial cohesive model.
\end{abstract}

Keywords: Steel fiber reinforced self-compacting concrete, single fiber pullout, cohesive model, inverse method.

\section{INTRODUCTION}

Short and randomly distributed fibers are often used to reinforce cementitious materials,

\footnotetext{
${ }^{1}$ Doctoral Student, Dept. of Civ. Engrg., School of Engrg., Univ. of Minho, Campus Azurém, Guimarães, Portugal. E-mail: vcunha@civil.uminho.pt.

${ }^{2}$ Assoc. Prof., Dept. of Civ. Engrg., School of Engrg., Univ. of Minho, Campus Azurém, Guimarães, Portugal. E-mail: barros@civil.uminho.pt.

${ }^{3}$ Assist. Prof., Dept. of Civ. Engrg., School of Engrg., Univ. of Minho, Campus Azurém, Guimarães, Portugal. E-mail: jsena@civil.uminho.pt.
} 
since they offer resistance to crack initiation and, mainly, to crack propagation. In steel fiber reinforced cementitious composites (SFRC) of low fiber volume fraction, the principal benefits of the fibers are effective after matrix cracking has occurred, since fibers crossing the crack guarantee a certain level of stress transfer between both faces of the crack, providing to the composite a residual strength, which magnitude depends on the fiber, matrix and fiber-matrix properties.

Over the past decade, concrete has been widely acknowledge as a three-phase material which includes the matrix, aggregates and an interface transition zone (ITZ), in which the latter is regarded as the weakest link. For conventional concrete the properties of the interface zone are well documented in the literature (Shah et al. 1995; Bentur and Mindess 2007). On the other hand, for new concretes containing distinct improved cement matrices (with low water/cement ratio), e.g. SFRSCC, the ITZ properties are not yet fully ascertained and much less are the involved mechanisms understood. With the advent of new composites materials of improved mechanical properties and advanced cement matrices the study of the fiber/matrix interface assumes a new interest. These matrices are rather innovative, since for attaining self-compactibility they have to fulfill high demands with regard of filling and passing ability, as well as segregation resistance. In order to accomplish these requirements, it should be used high percentage of fine materials, low water/binder-ratios, appropriate adjusted admixtures, and relatively high amounts of cement and fine additions. Moreover, the maximum aggregate dimension is usually smaller than the one used in conventional or high strength concretes. Considering the above-mentioned and that steel fibers and matrix are bonded together through a weak interface, study of the interfacial behavior is important for understanding the mechanical behavior of such composites, since properties of the composite are greatly influenced by this interface zone.

The effectiveness of a given fiber as a medium of stress transfer (and indirectly the fiber/matrix interface properties) is often assessed using a single fiber pullout test, where fiber slip is monitored as a function of the applied load on the fiber (Naaman and Najm 
1991; Banthia and Trottier 1994). In spite of the belief held in the past that no correlation exists between the behavior of fiber in a single fiber pullout test and its behavior in a real composite (Hughes and Fattuhi 1975; Maage 1977), the data derived from single pullout tests can give relevant contribution to optimize the properties of fiber reinforcement cement composites. The available research indicates that there is not an ideal test or model to fully predict the mechanical behavior of steel fiber reinforced concrete, even for the basic case of uniaxial tension, since the relationships withdrawn from the uniaxial tension test can not be representative of all fiber types and cement matrices. However, from the analysis of the fiber reinforcement mechanisms in a single pullout test, the key aspects of the overall behavior of a composite material tested under uniaxial tension can be assessed.

The post-cracking behavior of random discontinuous fiber reinforced brittle-matrix composites can be predicted by the use of a bridging stress-crack opening displacement relationship, $\sigma-w$. Several authors developed probabilistic-based micromechanical models for obtaining the $\sigma-w$ relationship (Visalvanich and Naaman 1983; Li et al. 1991; Maalej et al. 1995), since for quasi-brittle materials the stress-crack opening relationship that simulates the stress transfer between the faces of the crack has a significant impact on the behavior of a structure after its cracking initiation. The latter models, which are based on an averaging process of all the forces that are carried out by the fibers over a crack plane by modeling the main mechanisms on a single fiber pullout, can provide the general material composite behavior with reasonable accuracy.

The main scope of this study is to assess the pullout behavior of steel fibers from a SFRSCC medium and obtain the local bond stress-slip relationship. The influence of fiber embedded length, orientation and mechanical anchorage mechanism on the fiber pullout behavior is also studied. Fibers mechanically deformed, such is the case of hooked ended fibers, provide both higher peak pullout load and pullout dissipated energy than straight fibers. In spite of that, in the present work straight fibers were also tested with the main purpose of isolating the adherence bond from the mechanical bond provided by the hook. 
This makes it possible to separate assessment of the influence of the various mechanisms of bond. Furthermore, it allows to develop rational analytical models to describe bond in SFRC. For these purposes an experimental program was carried out, and an analytical model was implemented to obtain the local bond law by a back-analysis procedure.

\section{EXPERIMENTAL PROGRAM}

\section{Series and justification}

The pullout tests presented here may be divided into two main groups, according to the type of fibers used: hooked-end and straight. Within these two main groups, it was assessed the influence of the fiber embedded length $(10,20$ and $30 \mathrm{~mm})$ and fiber orientation $\left(0,30\right.$ and $\left.60^{\circ}\right)$ on the pullout response. Each series of the straight fibers comprises three specimens, whereas six specimens compose each series of the hooked fibers. In all performed tests only DRAMIX® RC-80/60-BN hooked-end steel fibers were used. straight fibers were obtained by cutting the hooked ends of the RC-80/60-BN fibers, with a pliers.

Code names were given to the test series, which consist on alphanumeric characters separated by underscore. The first character indicates the fiber type ( $\mathrm{S}$ - straight; $\mathrm{H}$ - hooked), the second string indicates the embedded length in $\mathrm{mm}$ (for instance, Lb10 represents a fiber embedded length of $10 \mathrm{~mm}$ ) and finally the last numeral indicates the fiber inclination angle with the fiber pullout load orientation, in degrees. Due to technical problems, the series S_Lb10_0 and S_Lb10_30 could not be correctly tested, therefore they are not presented.

\section{Preparation of specimens}

The pullout tests on single steel fibers were performed using cored concrete specimens. In order to produce the specimens, a special mould was designed, able to accommodate 87 fibers fixed at its bottom. This device was used to cast 87 pullout specimens simultaneously, allowing a correct placement of the fiber and keeping the desired embedded length and inclination angle for the fiber (see Fig. 1). After casting, the concrete slab was cured at a temperature of $20^{\circ} \mathrm{C}$ and a relative humidity of about $95 \%$. After 30 days, the concrete slab 
was unmoulded, and cylindrical specimens containing each one single fiber were drilled from the slab. The diameter and height of each specimen was $80 \mathrm{~mm}$.

\section{Materials}

\section{Mix composition}

The materials used in the composition of the SFRSCC, were: cement (C) CEM I 42.5R, limestone filler (LF), superplasticizer (SP) of third generation based on polycarboxilates (Glenium® 77SCC), water (W), three types of aggregates (fine river sand (FS), coarse river sand (CS) and crushed granite 5-12 mm (CA)) and DRAMIX® RC-80/60-BN hooked-end steel fibers. The adopted fiber has a length $\left(l_{f}\right)$ of $60 \mathrm{~mm}$, a $0.75 \mathrm{~mm}$ diameter $\left(d_{f}\right)$, an aspect ratio $\left(l_{f} / d_{f}\right)$ of 80 and a yield stress of $1100 \mathrm{MPa}$.

The method used for defining the composition of the SFRSCC, the mixing procedure and other properties of the SFRSCC in the fresh state can be found elsewhere (Barros et al. 2007). Table 1 includes the composition that has best fitted self-compacting requirements for the adopted fiber content, (Cf). Remark that, in Table 1, WS is the water necessary to saturate the aggregates and $\mathrm{W} / \mathrm{C}$ is the water/cement ratio. The WS parcel was not used to compute the $\mathrm{W} / \mathrm{C}$ ratio, but the water parcel from the superplasticizer was considered to compute the latter ratio.

\section{Properties of SFRSCC}

For testing the SFRSCC properties in the fresh state, the Abrams cone was used in inverted position (concrete flowed through the small orifice of the cone). A total spread of $720 \mathrm{~mm}$ was measured and no sign of segregation was detected as the mixture showed good homogeneity and cohesion.

The fiber pullout tests were performed at approximately 180 days after concrete casting. The concrete compressive strength was assessed by three cubic specimens with an edge length of $150 \mathrm{~mm}$. The average value of the concrete compressive strength, at the age of the fiber pullout tests, was 83.4 MPa with a coefficient of variation of $0.9 \%$. 


\section{Test setup}

The pullout tests were performed in a servo-hydraulic Lloyd LR30K machine with a capacity of $30 \mathrm{kN}$. The single-sided specimen is mounted in a steel supporting system, see Fig. 2. This frame incorporates a steel system composed by a plate connected to a cylinder that is fixed to the testing machine frame. The cylinder/machine connection allows free rotations of all the steel frame. A steel ring is coupled to the aforementioned steel system by three steel screws. The protruding end of the steel fiber is fastened to a standard "Lloyd" grip which allows a secure hold of the fiber.

For the measurement of the fiber pullout slip, three LVDT's (linear stroke $+/-5 \mathrm{~mm}$ ) were used. In order to exclude measuring deformations of the testing rig and fiber slip at the grip, the LVDT's were fixed at the upper steel ring and touching the bottom surface of an aluminium plate fixed to the fiber. The plate was fixed to the fiber with two fine screws and was used as a support for this LVDT configuration (Fig. 2). The deformation of the steel frame in which the LVDT's were fixed is marginal, due to its considerable stiffness. Since the three LVDT's were disposed around test specimen forming an angle of 120 degrees between consecutive LVDT's, the actual slip of the fiber is the average of the three LVDT's readouts. The closed-loop displacement control was performed by the testing machine internal displacement transducer, at a rate of $10 \mu \mathrm{m} / \mathrm{s}$.

\section{RESULTS AND DISCUSSION}

\section{Failure modes}

The totality of both hooked and straight aligned fibers were completely pulled out. In the case of hooked fibers, after debonding of the fiber-matrix interface, the hooked was fully straightened. This failure mode was designated as FM1. A similar failure mode, FM2, was observed for some inclined fibers, however, in opposite to aligned fibers, spalling of the matrix at the fiber bending point was observed. Nevertheless, the most common failure mode observed during the pullout tests of inclined hooked fibers was fiber rupture, FM3. Another observed failure mode, FM4, was by matrix spalling. In this case, the fiber was 
almost fully pulled out from the concrete specimen. However, when the embedded end of the fiber approaches the exit point of the concrete matrix, a portion of concrete near the fiber bending point was detached. This failure mode was only observed for a few fibers with an inclination angle of $60^{\circ}$ and an embedded length of $10 \mathrm{~mm}$. Premature fiber or matrix failure were observed, exclusively in pullout specimens with inclined fibers. Moreover, fiber rupture was the predominant failure mode for a $30^{\circ}$ inclination angle, whereas for an angle of $60^{\circ}$ and lower embedded lengths matrix failure was also registered. The fiber rupture observed for hooked inclined fibers was a result of both a strong and compact concrete matrix, and a good fiber anchoring in it. The failure modes observed for each series are indicated in Table 2. When more than one failure mode occurred for a specific series, the number of specimens corresponding to each failure type is indicated between parenthesis.

\section{Pullout load-slip curves}

The average pullout load-slip curves for the tested series are depicted in Fig. 3. In general, for both analyzed hooked and straight aligned fibers, the configuration of the pullout loadslip curve was similar, regardless the fiber embedded length but, as expected, the peak load and the dissipated energy increased with it (see Fig. 3(a)). In straight fibers, after the peak load was attained a sudden drop was observed, which corresponds to an abrupt increase of damage at the fiber-paste interface (unstable debond). Afterwards, fiber-paste friction was the commanding mechanism of the pullout behavior. In this part of the post-peak branch, the load decreased with the increase of slip, since the available frictional area decreases, as well as the roughness of the failure surface. On the other hand, the post-peak load decay in hooked fibers was not so abrupt than in straight fibers, since with the increase of the slip the fiber mechanical anchorage started to become progressively mobilized. At an approximately $4.5 \mathrm{~mm}$ slip (corresponding approximately to the straightened hook length), the pullout process occurs under frictional resistance in similitude to straight fibers.

In the case of hooked fibers with a $30^{\circ}$ inclination angle, as previously seen, two failure modes occurred, which were reflected into two distinct types of pullout-slip curves. In 
Fig. 3(b), the average curve is represented up to the slip where the fiber rupture took place, therefore the curve averaging was performed only up to a slip correspondent to the peak load. For some specimens, sudden load drops were observed before attaining the peak load. This was a consequence of matrix wedges that have spalled. After each completion of wedge spalling off, a new more stable wedge was formed, and the remaining fiber segment embedded in the matrix was then pulled out.

On the other hand, for the post-peak behavior of straight fibers with an inclination angle of $30^{\circ}$ the load also decreases with the increase of slip. Comparatively to the aligned straight fibers, the load decay is lesser abrupt, since the influence of the frictional resistance is more significant for inclined fibers.

A completely distinct behavior was observed for the series with an inclination angle of $60^{\circ}$ (Fig. 3(c)). As previously seen, the hooked series with the latter inclination angle failed by fiber rupture, with the exception of one specimen, whereas in the series of straight fibers were fully pulled out. As the inclination angle increased, the stresses concentration at the fiber exit point from the matrix increased, therefore the concrete matrix is more prone to cracking and spalling. In terms of pre-peak behavior, this was reflected in a significant loss of stiffness. Comparing, respectively, Fig. 3(b), and Fig. 3(c), it can be perceived that for the series with a $60^{\circ}$ angle, cracking and spalling started for a lower load level. Moreover, as a larger portion of concrete was pushed or pulled out, a larger fiber length can be more easily bent, which promotes the stiffness decrease up to the peak load. Regarding the post-peak in straight fibers, a straighter load decay was observed than in case of straight fibers aligned and with a $30^{\circ}$ angle, since for a $60^{\circ}$ inclination angle the frictional resistance due to the force component perpendicular to the fiber axis is much higher.

\section{Effect of the fiber embedded length}

In Table 2 are indicated both the average values of the peak pullout load, $N_{\text {max }}$, and the corresponding coefficient of variation, CoV. Generally, the $N_{\max }$ increased linearly with the embedded length for both hooked and straight fibers. The series H_Lb_60 was the only 
exception, since it was observed a decrease on the $N_{\text {max }}$ for a $20 \mathrm{~mm}$ embedded length. In the case of aligned fibers the influence of $L_{b}$ was more significant on the straight fibers, since an increase of more than $100 \%$ on $N_{\max }$ occurred, increasing $L_{b}$ from 20 to $30 \mathrm{~mm}$, while relatively small increments were registered for the hooked fibers. In fact, for hooked fibers the increment of $L_{b}$ from 10 to $30 \mathrm{~mm}$ provided an increase on the $N_{\max }$ of about $20 \%$. These results demonstrate that the pullout response of hooked fibers at given embedded length is predominantly influenced by the mobilization and straightening of the hook, which is in accordance with published findings (Naaman and Najm 1991; Robins et al. 2002). For inclined straight fibers, in resemblance to the aligned hooked fibers, the increase of $N_{\max }$ with the increase of $L_{b}$ was also relatively small, respectively, $17 \%$ and $23 \%$ for an inclination angle of $30^{\circ}$ and $60^{\circ}$ (for the comparison between $L_{b}=20 \mathrm{~mm}$ and $L_{b}=30 \mathrm{~mm}$ ). These results point out that, in inclined fibers, the enhanced frictional resistance due to the force component normal to the fiber axis (due to the fiber inclination) plays a more important role on the peak pullout load than the embedded length. This is even more relevant on the inclined hooked fibers, since both mechanical deformation of the hook and frictional resistance actuate together. Therefore, for the latter series, the increase of $N_{\max }$ with $L_{b}$ will be smaller than for straight fibers. Moreover, this increment decreases with the inclination angle $\left(20 \%, 15 \%\right.$ and $7 \%$, respectively for the hooked series with a $0^{\circ}, 30^{\circ}$ and $60^{\circ}$ - these values correspond for the comparison between $L_{b}=10 \mathrm{~mm}$ and $L_{b}=30 \mathrm{~mm}$ ).

The average values of the slip at peak pullout load, $s_{\text {peak }}$, and the corresponding coefficient of variation, $\mathrm{CoV}$, are indicated in Table 2. For both straight and hooked aligned fibers a slight increase of $s_{\text {peak }}$ with $L_{b}$ was observed, whereas for inclined fibers no clear tendency of the influence of the embedded length on the $s_{\text {peak }}$ was found. This aspect can be justified by the high values obtained for the $\mathrm{CoV}$.

A detailed overview of the pullout toughness of the current experimental tests can be found elsewhere (Cunha et al. 2007). Nevertheless, the main conclusion that can be withdrawn is that, the overall toughness is markedly influenced by the type of failure mode, since 
fiber fracture significantly reduces the toughness when compared to the cases where fibers underwent a complete pullout.

\section{Effect of the fiber inclination angle}

In general, the $N_{\max }$ increases up to a inclination angle of $30^{\circ}$ and then decreases for $60^{\circ}$ angle. For both hooked and straight fibers the highest maximum pullout load was observed for an inclination angle of $30^{\circ}$. However, the increase of the maximum pullout load with the inclination angle was more significant on the straight fiber series. The series of straight fibers with a $30^{\circ}$ inclination angle had a $N_{\max } 30 \%$ and $125 \%$ higher than the aligned straight fiber series, respectively, for $L_{b}=30 \mathrm{~mm}$ and $L_{b}=20 \mathrm{~mm}$. On the other hand, for the hooked fiber series with a $30^{\circ}$ inclination angle, the $N_{\max }$ is just $7 \%$ to $15 \%$ higher than aligned hooked fiber series. In spite of the increase of the frictional pullout component with the inclination angle, increasing the angle from $30^{\circ}$ to $60^{\circ}$ led to a slight decrease on the $N_{\max }$. Remember that for the series of inclined hooked fibers fiber rupture was the commanding failure mode. Moreover, the average tensile strength load was smaller for the series with a $60^{\circ}$ inclination angle than for $30^{\circ}$.

The slip at peak load, $s_{\text {peak }}$, increased with the inclination angle for both hooked and straight fibers, especially in the straight fibers. From $0^{\circ}$ to $30^{\circ}$ a slight increase on the $s_{\text {peak }}$ was observed, while a significant increase of $s_{\text {peak }}$ was registered from $30^{\circ}$ to $60^{\circ}$. In fact, for the series of straight fibers with $60^{\circ}$ inclination angle, the $s_{\text {peak }}$ was approximately 5 to 9 times higher than for a $30^{\circ}$ angle, whereas for the hooked series it was 1.3 to 2.3 times higher. The significant higher values of $s_{\text {peak }}$ for a $60^{\circ}$ angle can be ascribed to other additional mechanisms that usually occur on inclined fibers in opposite to aligned fibers. As the fiber inclination angle increases, the stresses concentrated at the fiber bending point also increase. This leads to a more significant portion of concrete that crushes or pushes off at the crack plane. As the volume of concrete that spalls is higher, a larger fiber length is subjected to bending, resulting an additional measured slip due to the fiber deformation. So, for large inclination angles, such as $60^{\circ}$, the slip includes a significant parcel which is due 
to fiber deformation.

\section{ANALYTICAL RESEARCH ON THE PREDICTION OF THE FIBER PULLOUT Developed model and its performance}

The mathematical representation of the pullout phenomenon is often expressed by a second order differential equation established in terms of forces (Naaman et al. 1991; Sujivorakul et al. 2000; Banholzer et al. 2005). However, since in the present model the deformation of the concrete at the interface with the fiber was neglected, the differential equation was derived in terms of slip, after (Focacci et al. 2000; Sena-Cruz et al. 2006). This model was used for both straight and hooked aligned fibers. However, for hooked fibers, to simulate the mechanical anchorage resistance provided by hooked ends, an additional spring component at the embedded end of the fiber was included, Fig. 4. The pullout phenomenon of hooked fibers is markedly a three dimensional problem. Nevertheless, it was approached as a two dimensional problem, since it seemed feasible to model the interfacial bond of the hooked fiber as a two dimensional axisymmetric problem, and the hook length is relatively smaller than the fiber length.

\section{Formulation}

From the equilibrium of the free body of an infinitesimal length $d x$ of a fiber bonded to a concrete matrix (see Fig. 4(c)) the following second order differential equation that governs the local bond phenomena of the fiber - matrix interface can be established:

$$
\frac{d^{2} s}{d x^{2}}=\frac{P_{f}}{E_{f} A_{f}} \cdot \tau
$$

where $\tau=\tau(s(x))$ is the local bond shear stress acting on the contact surface between fiber and concrete, and $s$ is the slip, i.e. the relative displacement between the fiber and the surrounding concrete. In Eq. 1, $E_{f}, A_{f}$ and $P_{f}$ are the Young modulus, cross section area and perimeter of the fiber, respectively. The contribution of the concrete deformability in the slip assessment was neglected, since it is much lower than the inelastic deformations of 
the fiber. Several authors have neglected this component, on the evaluation of the bond-slip relationship of reinforcing bars or of FRP reinforcement (Focacci et al. 2000; Sena-Cruz et al. 2006). In spite of this belief, in order to validate this assumption for small fibers, an analytical model which took into account the deformation of the matrix surrounding the fiber was used in the assessment of the pullout load - slip relationship (Sujivorakul et al. 2000). This model was used to evaluate the influence of the matrix deformation, $\epsilon_{c}$, on the pullout response. For the current fibers lengths and matrix stiffness, it was concluded that, $\epsilon_{c}$ does not influence the slip value determination.

Consider a steel fiber embedded on a concrete matrix over a bond length $\tilde{L}_{b}\left(=L_{b}\right)$, where $N$ is the generic applied pullout force, and $s_{f}$ and $s_{l}$ are, respectively, the free and loaded end slips, with respect to the longitudinal axis of the fiber, $x$, starting at the free end $\left(s_{f}=s(x=0) ; s_{l}=s\left(x=\tilde{L}_{b}\right)\right)$. When the fiber is slipping due to an applied pullout load, $\bar{N}$, the following functions can be evaluated along the fiber bond length: slip, $s(x)$; bond shear stress, $\tau(x)$; fiber strain, $\epsilon_{f}(x)$; and the axial force, $N(x)$.

The slip diagram along the fiber, $s(x)$, can be regarded as the sum of two components. A constant component, $s_{f}$, which produces a rigid body displacement of the fiber, and a $s_{d}(x)$ component that results from the deformation of the fiber. Moreover, for any point $x$ of the fiber embedded length, just the $s_{d}(x)$ component that results in a fiber length change, and, therefore, contributing to the fiber deformation energy. Likewise, the axial force along the fiber, $N(x)$, can be decomposed in two components. A constant component, $N_{s p}$, due to the spring load (only in the case of hooked fibers) and the $N^{\prime}(x)$ component. Only the latter contributes to the fiber deformation energy, since in the adopted model it was assumed that $N_{s p}$ does not produce a fiber length change. Therefore, the fiber deformation at a point $x$ is obtained from $\epsilon_{f}(x)=N^{\prime}(x) /\left(E_{f} A_{f}\right)$. The relationship between pullout load and slip can be determined using either an energy approach (Focacci et al. 2000) or an equilibrium approach (Naaman et al. 1991). In the present work the energy approach was adopted. From balancing the work performed by the external forces and the internal work due to the 
elastic energy of the fiber, the following equation is obtained (Cunha et al. 2007):

$$
N^{\prime}\left(\tilde{L}_{b}\right)=\sqrt{2 E_{f} \cdot A_{f} \cdot P_{f} \int_{s_{f}}^{s\left(x=\tilde{L}_{b}\right)} \tau(s) d s}
$$

which allows to determine the generic applied pullout force for a straight fiber or, in the case of a hooked fiber, the pullout load component at the fiber loaded end due to the interfacial bond of the fiber. Remarking that in the case of hooked fibers, the generic applied load is $\bar{N}=N^{\prime}\left(x=\tilde{L}_{b}\right)+N_{s p}$, for this type of fibers the generic applied load is given by:

$$
\bar{N}=N_{s p}+\sqrt{2 E_{f} \cdot A_{f} \cdot P_{f} \int_{s_{f}}^{s\left(x=\tilde{L}_{b}\right)} \tau(s) d s}
$$

In the present method, both numerical and experimental entities are simultaneously used, hence the experimental one was distinguished by an overline, i.e $\bar{N}^{i}$ stands for the pullout load experimentally measured in the $i$-th scan read-out. Additionally, remark that for a straight fiber $N^{\prime}\left(x=\tilde{L}_{b}\right)=\bar{N}$. On the other hand, for a hooked fiber, $\bar{N}=N^{\prime}\left(\tilde{L}_{b}\right)+N_{s p}$.

The analytical bond stress-slip relationship used in the present work is defined by Eq. 4, where $\tau_{m}$ and $s_{m}$ are, respectively, the bond strength and its corresponding slip. Parameter $\alpha$ defines the shape of the pre-peak branch, whereas $\alpha^{\prime}$ and $s_{1}$ define the shape of the postpeak branch of the curve. These two equations were selected due to its easiness and aptitude to accurately model the local bond stress-slip behavior, as previously ascertained by several researchers (Stang and Aarre 1992; Lorenzis et al. 2002; Sena-Cruz et al. 2006).

$$
\tau(s)=\tau_{m}\left(\frac{s}{s_{m}}\right)^{\alpha}, s \leq s_{m} \wedge \tau(s)=\tau_{m} \frac{1}{1+\left(\frac{s-s_{m}}{s_{1}}\right)^{\alpha^{\prime}}}, s>s_{m}
$$

The mechanical component of bond, $N_{s p}$, was acquired by subtracting the experimental average curve of the aligned hooked series to the corresponding experimental average curve of the straight series, i.e. with the same $L_{b}$ (see Fig. $3(\mathrm{a})$ ). Both the envelope of the mechanical hook mechanism obtained for the series H_Lb20 and H_Lb30, and its analytical 
simulation are depicted in Fig. 5. Looking upon the mechanical component envelope (Fig 5), it can be observed that the shaded area is relatively tight, which reveals that the mechanical component of bond is not influenced by the embedment length. This will not be true if the embedment length is smaller than the length of the hooked end (Robins et al. 2002), which is not the case of the present work.

The fiber pullout tests provide in terms of pullout load, $\bar{N}$, and loaded end slip, $\bar{s}_{l}$ several scan read-outs, being $\bar{s}_{l}^{i}$ and $\bar{N}^{i}$ the values of the $i$-th experimental scan read-out. Regarding these experimental results, the set of unknown parameters of the local bond relationship represented by Eq. 4 will be obtained in order to fit the differential Eq. 1 as accurately as possible. For this purpose computational code was developed and implemented. The second order differential Eq. 1 included in the algorithm is solved by the Runge-KuttaNyström (RKN) method (Kreyszig 1993). The algorithm is built up from the following main steps (Cunha et al. 2007):

1. the $\tau-s$ relationship is defined attributing values to the unknown parameters. The error, $e$, defined as the area between the experimental and analytical curves, is initialized;

2. the loaded end slip is calculated at the onset of the free end slip, $\tilde{s}_{l}$, (see Module A in Fig. 6);

3. for the experimental $i$-th scan reading, the loaded end slip, $\bar{s}_{l}^{i}$, and the pullout load, $\bar{N}$ are read;

4. taking the loaded end slip, $\bar{s}_{l}^{i}$, and using Eq. 1, the pullout load at the loaded end, $N^{i}\left(s_{l}^{i}\right)$, is evaluated. In this case the following two loaded end slip conditions must be considered:

i) if $\bar{s}_{l}^{i}<\tilde{s}_{l}$, the determination of $N^{i}\left(s_{l}^{i}\right)$ must take into account that the effective bond length is smaller than the fiber embedded length (see Module B on Fig. 6). For the case of hooked fibers, the mechanical anchorage contribution is not 
considered, since the fiber is not yet fully debonded;

ii) if $\bar{s}_{l}^{i} \geq \tilde{s}_{l}$, the evaluation of $N^{i}\left(s_{l}^{i}\right)$ is based on Module C (see Fig. 6). In this module the contribution of the hooked-end, $N_{s p}\left(s_{l}^{i}\left(L_{b}\right)\right)$, is assessed by the equations presented in this section;

5. the error associated with $N^{i}\left(s_{l}^{i}\right)$ is calculated. This error is the area between the experimental $\left(A_{\text {exp }, f}^{i}\right)$ and numerical $\left(A_{\text {num }, f}^{i}\right)$ curves. The points $\left(\bar{s}_{l}^{i-1}, N^{i-1}\left(s_{l}^{i-1}\right)\right)$ and $\left(\bar{s}_{l}^{i}, N^{i}\left(s_{l}^{i}\right)\right)$ are used to define the numerical curve, whereas the experimental curve is represented by the points $\left(\bar{s}_{l}^{i-1}, \bar{N}^{i-1}\right)$ and $\left(\bar{s}_{l}^{i}, \bar{N}^{i}\right)$;

In Modules B and C the Newton Raphson method is used. Whenever the Newton Raphson method fails, the bisection method is used as an alternative. The determination of the unknown parameters defining the bond stress-slip relationship, $\tau-s$, was performed by a back-analysis, i.e. determining the $\tau-s$ relationship that minimizes the difference between the numerical and experimental load-slip curves with a minimum error, e. Additionally, two restrictive conditions were added in order to assure similar values between the numerical and experimental peak pullout load and its corresponding slip (with a tolerance smaller than $2 \%$ ). The back-analysis was performed by the exhaustive search method.

\section{Appraisal of the model performance}

The values of the parameters of the adopted local bond stress-slip relationships (see Eq. 4) were determined using the numerical strategy described in the previous section. The local bond stress-slip relationship for each series was calibrated from the average experimental pullout load-slip curve. In the model, a Young modulus, $E_{f}$, of $200 \mathrm{GPa}$, a cross sectional area, $A_{f}$, of $0.562 \mathrm{~mm}^{2}$ and a cross section perimeter, $P_{f}$, of $2.356 \mathrm{~mm}$ were adopted.

In Fig. 7 is depicted the numerical pullout load-slip relationship and the experimental envelope for straight and hooked aligned series. The values of the parameters defining the local bond relationships, obtained by back analysis, are included in Table 3. Moreover, the corresponding normalized error, $\bar{e}$, is also included, which was defined as the ratio between 
$e$ and the area under the experimental curve.

The numerical curves fitted the experimental data with high accuracy, even for high slips, as evinced by the quite low values of the normalized error of each series. The average values and the corresponding coefficients of variation of the local bond law parameters are also indicated in Table 3. In spite of the accurateness of the numerical simulation, the coefficients of variation of the bond law parameters were quite high. This fact can be related to the method used in back-analysis (exhaustive search), since the parameters search procedure is based on a previously defined range and step, i.e, the parameter variables are discrete. Moreover, only one objective function was used, i.e., the difference between the area under the experimental and numerical curves, to determine the best fit for each series.

\section{CONCLUSIONS}

The experimental results of steel fibers pullout tests on a SFRSCC medium were presented and discussed. The influence of the fiber orientation $\left(0^{\circ}, 30^{\circ}\right.$ and $\left.60^{\circ}\right)$, as well as, the fiber embedded length $(10,20$ and $30 \mathrm{~mm})$ on the fiber pullout behavior was studied. Additionally, the role of the hooked ends of the fiber on the overall fiber pullout behavior is attained by isolating the contribution of the frictional bond component. Finally, the fiber pullout phenomena was modeled with an analytical model. For this purpose, the developed analytical model was implemented in a computational code. Using this code, the local bond stress-slip law parameters were obtained by back-analysis.

Regarding the experimental tests, in general, the maximum pullout load had an almost linear increase with the embedded length for both hooked and straight fibers. However, this increase was more significant on the straight fibers, since the pullout response of hooked fibers, regardless the fiber embedded length, is predominantly influenced by the mobilization and straightening of the fiber hooked-end. Regarding the effect of the fiber orientation angle, the maximum pullout load increased up to an inclination angle of $30^{\circ}$ and then decreased for a $60^{\circ}$ inclination angle. For both hooked and straight fibers the highest maximum pullout load was observed for an inclination angle of $30^{\circ}$. 
For both straight and hooked aligned fibers a slight increase of the slip at peak load with the fiber embedded length was observed, whereas for inclined fibers no clear tendency of the influence of the embedded length on the slip at peak load was found. On the other hand, regarding the influence of the fiber orientation angle, a slight increase on the slip at peak load was observed for a $30^{\circ}$ angle, whereas for a $60^{\circ}$ angle the slip at peak stress increased considerably. The significant increase of the slip at peak load for a $60^{\circ}$ angle can be ascribed to other additional mechanisms that usually occur on the pullout of inclined fibers in opposite to aligned fibers.

The developed analytical model was able to simulate with high accuracy the recorded experimental pullout load-slip curves, even for high slips, for both hooked and straight aligned fibers. In spite of the accurateness of the numerical simulation, the coefficients of variation of the bond law parameters were quite high. This fact can be related to the method used in back-analysis (exhaustive search), hence additional study should be performed in order to ascertain the local bond law parameters with lower coefficients of variation.

\section{ACKNOWLEDGMENTS}

The study reported in this paper is part of the research program PABERPRO - Conception and implementation of a production system of prefabricated sandwich steel fiber reinforced panels supported by POCI 2010-IDEIA, Project No 13-05-04-FDR-00007, contract reference ADI/2007/V4.1/0049. This project involves the Companies PREGAIA and CIVITEST, and the University of Minho. The authors wish to acknowledge the materials generously supplied by Bekaert (fibers), SECIL (cement), Degussa (superplasticizer), and Comital (limestone filler). The first author wishes also to acknowledge the grant SFRH/BD/18002/2004, provided by FCT. 


\section{APPENDIX I. REFERENCES}

Banholzer, B., Brameshuber, W., and Jung, W. (2005). "Analytical simulation of pull-out tests - the direct problem." Cement \& Concrete Composites, 27, 93-101.

Banthia, N. and Trottier, J. (1994). "Concrete reinforced with deformed steel fibers, Part I: Bond slip mechanisms." ACI Materials Journal, 91(5), 435-446.

Barros, J. A. O., Pereira, E. B., and Santos, S. P. F. (2007). "Lightweight panels of steel fibre reinforced self-compacting concrete." Journal of Materials in Civil Engineering - ASCE, 9(4), 295-304.

Bentur, A. and Mindess, S. (2007). Fibre reinforced cementitious composites. Taylor \& Francis, London.

Cunha, V., Barros, J., and Sena-Cruz, J. (2007). "Pullout of hooked-end steel fibres in self-compacting concrete." Report no., 07-DEC/E-06, University of Minho, Portugal, http://www.civil.uminho.pt/composites/Publications/2006/TR2006_001_06_DEC-E04.pdf.

Focacci, F., Nanni, A., and Bakis, C. (2000). "Local bond-slip relationship for FRP reinforcement in concrete." Journal of Composites for Construction ASCE, 4(1), 24-31.

Hughes, B. P. and Fattuhi, N. I. (1975). "Fiber bond strengths in cement and concrete." Magazine of Concrete Research, 27(92), 161-166.

Kreyszig, E. (1993). Advanced Engineering mathematics. John Wiley \& Sons, Inc.

Li, V. C., Wang, Y., and Baker, S. (1991). "A micromechanical model of tension softening and bridging toughning of short random fiber reinforced britle matrix composites." $J$. Mech. Phys. Solids, 39(5), 607-625.

Lorenzis, L. D., Rizzo, A., and Tegola, A. L. (2002). "A modified pull-out test for bond of near-surface mounted frp rods in concrete." Journal of Composites Part B: Engineering, 33(8), 589-603.

Maage, M. (1977). "Interaction between steel fibres and cement-based matrices." Materials and Structures, Research and Testing (RILEM), 10(59), 297-301. 
Maalej, M., Li, V. C., and Hashida, T. (1995). "Effect of fiber rupture on tensile properties of short fiber composites." ASCE Journal of Engineering Mechanics, 121(8), 903-913.

Naaman, A. E. and Najm, H. (1991). "Bond-slip mechanisms of steel fibers in concrete." ACI Materials Journal, 88(2), 135-145.

Naaman, A. E., Namur, G. G., Alwan, J. M., and Najm, H. S. (1991). "Fiber pullout and bond slip I: Analytical study." Journal of Structural Engineering ASCE, 117(9), 27692790.

Robins, P., Austin, S., and Jones, P. (2002). "Pull-out behaviour of hooked steel fibres." RILEM Journal of Engineering Mechanics, 35(251), 434-442.

Sena-Cruz, J. M., Barros, J. A. O., Gettu, R., and Azevedo, A. F. M. (2006). "Bond behavior of near-surface mounted cfrp laminate strips under monotonic and cyclic loading.." Journal of Composites in Construction ASCE, 10(4), 295-303.

Shah, S. P., Swartz, S. E., and Ouyang, C. (1995). Fracture machanics of concrete (application of fracture mechanics to concete, rock and other quasi-britle materials). John Wiley \& Sons, Inc.

Stang, H. and Aarre, T. (1992). "Evaluation of crack width in FRC with conventional reinforcement." Cement \& Concrete Composites, 14(1), 143-154.

Sujivorakul, C., Waas, A. M., and Naaman, A. (2000). "Pullout response of a smooth fiber with an end anchorage." Journal of Engineering Mechanics, 126(9), 986-993.

Visalvanich, K. and Naaman, A. E. (1983). "Fracture model for fiber reinforced concrete." ACI Journal, 80(2), 128-138. 


\section{APPENDIX II. NOTATION}

The following symbols are used in this paper:

$$
\begin{aligned}
& A_{f}=\text { fiber cross sectional area; } \\
& A_{\text {exp }, f}^{i}, A_{\text {num }, f}^{i}=\text { area of the experimental and numerical pullout curves, respectively; } \\
& d_{f}=\text { diameter of fiber; } \\
& E_{f}=\text { elasticity modulus of the fiber; } \\
& L_{b}=\text { fiber embedded length; } \\
& \tilde{L}_{b}=\text { adopted embedded length for the analytical model; } \\
& L_{e f}=\text { effective embedded length; } \\
& l_{f}=\text { length of fiber; } \\
& N=\text { axial force of the fiber; } \\
& \bar{N}=\text { pullout load; } \\
& N_{\max }=\text { peak pullout load; } \\
& N_{s p}=\text { axial force component due to the spring load; } \\
& P_{f}=\text { perimeter of the fiber cross section; } \\
& s=\text { local slip between fiber/matrix; } \\
& s_{f}, s_{l}=\text { loaded and free end slips, respectively; } \\
& \tilde{s}_{l}=\text { loaded end slip at the onset of the free end slip; } \\
& s_{1}, s_{m}=\text { parameters of the local bond-slip law; } \\
& s_{\text {peak }}=\text { slip at peak pullout load; } \\
& \alpha, \alpha^{\prime}=\text { parameters of the local bond-slip law; } \\
& \epsilon_{f}=\text { local strain of the fiber; } \\
& \tau=\text { shear stress at interface between fiber and matrix; and } \\
& \tau_{m}=\text { bond strength of interface between fiber and matrix. }
\end{aligned}
$$




\section{APPENDIX III. DERIVATION OF EQ. 2}

Considering a generic fiber cross section, constrained by $0 \leq \bar{x} \leq \tilde{L}_{b}$, and that the fiber lateral surface over embedded length is $\Omega=P_{f} \cdot \bar{x}$, the work performed by external forces acting on the range $0 \leq \bar{x} \leq \tilde{L}_{b}$ is:

$$
W_{e x t}=\int_{\Omega}\left(\int_{s_{f}}^{s(x)} \tau(s) d s\right) d \Omega=P_{f} \int_{0}^{\bar{x}}\left(\int_{s_{f}}^{s(x)} \tau(s) d s\right) d x
$$

On the other hand, remarking $V_{f}=A_{f} \cdot \bar{x}$ as the fiber volume over the embedded length, the elastic energy of the fiber is:

$$
\begin{aligned}
W_{i n t} & =\int_{V_{f}}\left(\int_{0}^{\epsilon(x)} \sigma_{f}\left(\epsilon_{f}\right) d \epsilon\right) d V_{f}=A_{f} \int_{0}^{\bar{x}}\left(\int_{0}^{\epsilon(x)} E_{f} \epsilon_{f} d \epsilon\right) d x \\
& =\frac{A_{f}}{2 E_{f}} \int_{0}^{\bar{x}} \sigma_{f}^{2}(x) d x
\end{aligned}
$$

From Equations 5 and 6 is obtained:

$$
\int_{0}^{\bar{x}}\left(P_{f} \int_{s_{f}}^{s(x)} \tau(s) d s-\frac{A_{f}}{2 E_{f}} \sigma_{f}^{2}(x)\right) d x=0
$$

Since Equation 7 must be satisfied for each value of $0 \leq \bar{x} \leq \tilde{L}_{b}$, this equation may be rewritten as:

$$
P_{f} \int_{s_{f}}^{s(x)} \tau(s) d s-\frac{A_{f}}{2 E_{f}} \sigma_{f}^{2}(x)=0
$$

At $x=\tilde{L}_{b}$ equation 8 becomes:

$$
P_{f} \int_{s_{f}}^{s\left(x=\tilde{L}_{b}\right)} \tau(s) d s-\frac{N^{\prime 2}}{2 E_{f} A_{f}}=0
$$


Cunha, V.M.C.F.; Barros, J.A.O.; Sena Cruz, J.M. (2010) "Pullout Behavior of Steel Fibers in Self-Compacting Concrete." Journal of Materials in Civil Engineering, 22(1), 1-9.

$$
N^{\prime}=\sqrt{2 E_{f} \cdot A_{f} \cdot P_{f} \int_{s_{f}}^{s\left(x=\tilde{L}_{b}\right)} \tau(s) d s}
$$


Cunha, V.M.C.F.; Barros, J.A.O.; Sena Cruz, J.M. (2010) "Pullout Behavior of Steel Fibers in Self-Compacting Concrete." Journal of Materials in Civil Engineering, 22(1), 1-9.

\section{List of Tables}

1 Final composition for $1 \mathrm{~m}^{3}$ of SFRSCC. . . . . . . . . . . . . . . . 24

2 Overview of the experimental results. . . . . . . . . . . . . 25

3 Parameters for the local bond stress-slip relationship obtained by back analysis for the aligned series. . . . . . . . . . . . . . . . . 26 
Cunha, V.M.C.F.; Barros, J.A.O.; Sena Cruz, J.M. (2010) "Pullout Behavior of Steel Fibers in Self-Compacting Concrete." Journal of Materials in Civil Engineering, 22(1), 1-9.

TABLE 1. Final composition for $1 \mathrm{~m}^{3}$ of SFRSCC.

\begin{tabular}{c|ccccc}
\hline \multirow{3}{*}{$\begin{array}{c}\text { Cf } \\
(\mathrm{kg})\end{array}$} & $\begin{array}{c}\text { Paste/Total } \\
\text { volume }(\%)\end{array}$ & $\begin{array}{c}\text { Cement } \\
(\mathrm{kg})\end{array}$ & $\begin{array}{c}\mathrm{LF} \\
(\mathrm{kg})\end{array}$ & $\begin{array}{c}\text { Water } \\
\left(\mathrm{dm}^{3}\right)\end{array}$ & $\begin{array}{c}\text { WS } \\
\left(\mathrm{dm}^{3}\right)\end{array}$ \\
\cline { 2 - 6 } 30 & 0.34 & 359.4 & 312.2 & 96.9 & 64.7 \\
\hline & $\mathrm{SP}$ & $\mathrm{FS}$ & $\mathrm{CS}$ & $\mathrm{CA}$ & $\mathrm{W} / \mathrm{C}$ \\
& $\left(\mathrm{dm}^{3}\right)$ & $(\mathrm{kg})$ & $(\mathrm{kg})$ & $(\mathrm{kg})$ & - \\
& 6.9 & 108.2 & 709.4 & 665.2 & 0.29 \\
\hline
\end{tabular}


TABLE 2. Overview of the experimental results.

\begin{tabular}{|c|c|c|c|c|c|}
\hline Series & Failure mode & $\begin{array}{c}N_{\max } \\
{[\mathrm{N}]}\end{array}$ & $\begin{array}{c}\mathrm{CoV} \\
{[\%]}\end{array}$ & $\begin{array}{l}s_{\text {peak }} \\
{[\mathrm{mm}]}\end{array}$ & $\begin{array}{c}\mathrm{CoV} \\
{[\%]}\end{array}$ \\
\hline S_Lb10_60 & $F M_{4}$ & 154.2 & 43.8 & 3.34 & 45.6 \\
\hline S_Lb20_0 & $F M 1$ & 77.4 & 2.0 & 0.12 & 11.8 \\
\hline S_Lb20_30 & $F M 2$ & 173.5 & 18.2 & 0.19 & 7.4 \\
\hline S_Lb20_60 & $F M 2$ & 172.8 & 8.7 & 2.02 & 2.0 \\
\hline S_Lb30_0 & $F M 1$ & 155.2 & 9.7 & 0.25 & 14.4 \\
\hline S_Lb30_30 & $F M 2$ & 203.7 & 13.8 & 0.38 & 32.3 \\
\hline S_Lb30_60 & $F M 2$ & 189.4 & 15.0 & 2.17 & 11.8 \\
\hline H_Lb10_0 & $F M 1$ & 321.8 & 5.6 & 0.59 & 8.7 \\
\hline H_Lb10_30 & FM2(2); FM3(4) & 360.9 & 13.9 & 0.94 & 11.4 \\
\hline H_Lb10_60 & FM3 $(5) ; F M 4(1)$ & 342.0 & 2.3 & 2.40 & 20.8 \\
\hline H_Lb20_0 & $F M 1$ & 347.8 & 2.8 & 0.65 & 9.4 \\
\hline H_Lb20_30 & FM2(2); FM3(4) & 400.1 & 4.9 & 1.00 & 9.7 \\
\hline H_Lb20_60 & $F M 3$ & 335.2 & 3.0 & 2.33 & 15.1 \\
\hline H_Lb30_0 & $F M 1$ & 388.2 & 1.6 & 0.69 & 11.0 \\
\hline H_Lb30_30 & FM3 & 416.0 & 3.4 & 0.80 & 19.3 \\
\hline H_Lb30_60 & FM3 & 365.1 & 2.5 & 2.64 & 23.2 \\
\hline
\end{tabular}

FM1 - Fiber pullout; FM2 - Fiber pullout with matrix spalling; FM3 - Fiber rupture; FM4 - Matrix spalling. 
Cunha, V.M.C.F.; Barros, J.A.O.; Sena Cruz, J.M. (2010) "Pullout Behavior of Steel Fibers in Self-Compacting Concrete." Journal of Materials in Civil Engineering, 22(1), 1-9.

TABLE 3. Parameters for the local bond stress-slip relationship obtained by back analysis for the aligned series.

\begin{tabular}{l|cccccc}
\hline Series & $s_{m}[\mathrm{~mm}]$ & $\tau_{m}[\mathrm{MPa}]$ & $\alpha$ & $\alpha^{\prime}$ & $s_{1}[\mathrm{~mm}]$ & $\bar{e}[\%]$ \\
\hline S_Lb20_0 & 0.14 & 1.77 & 0.60 & 0.22 & 0.44 & 3.2 \\
S_Lb30_0 & 0.24 & 2.27 & 0.69 & 0.42 & 1.30 & 5.0 \\
H_Lb10_0 & 0.25 & 1.61 & 0.22 & 0.88 & 0.53 & 4.3 \\
H_Lb20_0 & 0.23 & 1.80 & 0.84 & 0.45 & 1.10 & 2.2 \\
H_Lb30_0 & 0.14 & 2.10 & 0.89 & 0.42 & 2.21 & 1.9 \\
\hline \multirow{2}{*}{ Average } & 0.20 & 1.91 & 0.65 & 0.48 & 1.11 & \\
& $(24 \%)$ & $(11 \%)$ & $(37 \%)$ & $(45 \%)$ & $(57 \%)$ & - \\
\hline
\end{tabular}

Values in parenthesis are the coefficients of variation. 


\section{List of Figures}

1 Casting mould for the pullout specimens. . . . . . . . . . . . . . . 28

2 Configuration of the single fiber pullout test. . . . . . . . . . . . . . . . 29

3 Average pullout load-slip curves for a fiber inclination angle: (a) 0 degrees, (b) 30 degrees and (c) 60 degrees. . . . . . . . . . . . . . . . . . 30

4 Axisymmetric pullout model. . . . . . . . . . . . . . . . . . . . 31

5 Analytical simulation of the hook mechanical contribution. . . . . . . . . . 32

6 Modules A, B and $\mathrm{C}$ of the algorithm. . . . . . . . . . . . . . . 33

7 Pullout load-slip numerical simulation for the series with an embedded length

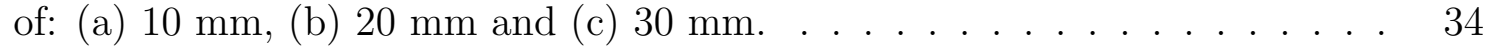




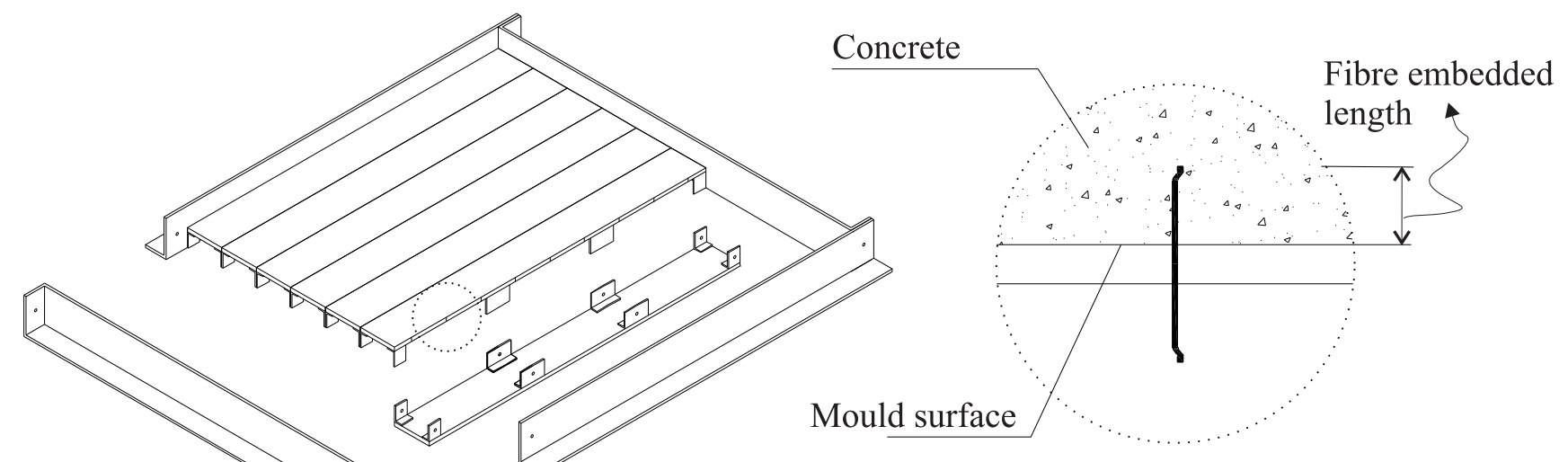

FIG. 1. Casting mould for the pullout specimens. 
Cunha, V.M.C.F.; Barros, J.A.O.; Sena Cruz, J.M. (2010) "Pullout Behavior of Steel Fibers in Self-Compacting Concrete." Journal of Materials in Civil Engineering, 22(1), 1-9.

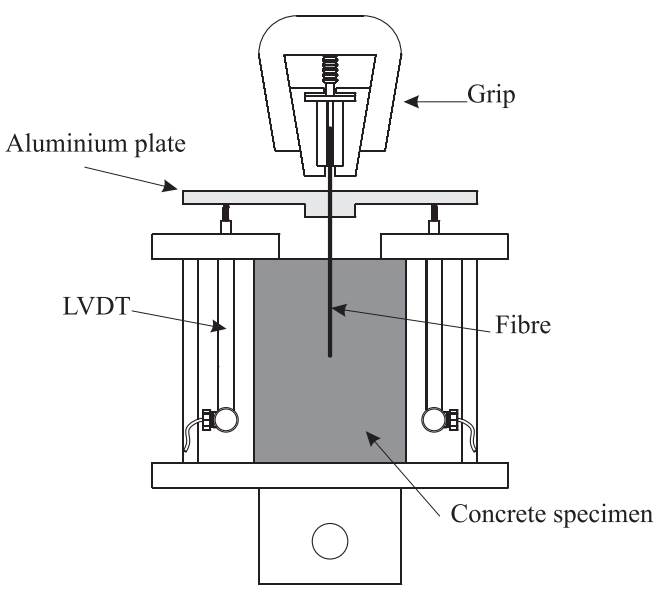

(a)

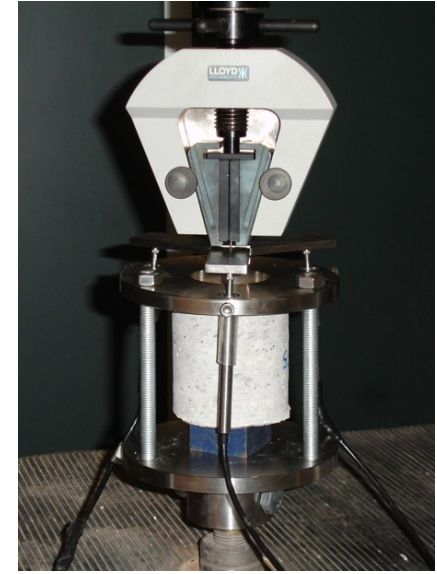

(b)

FIG. 2. Configuration of the single fiber pullout test. 

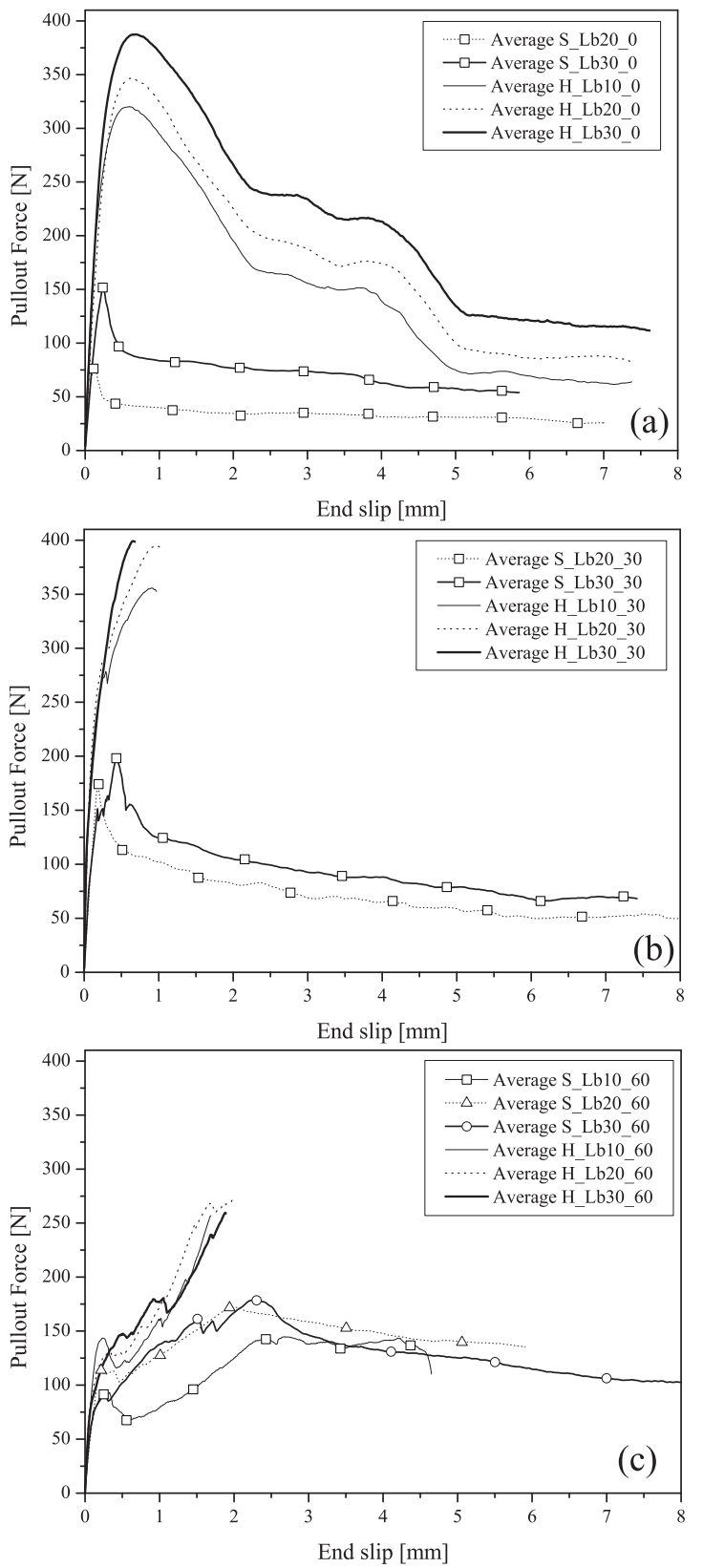

FIG. 3. Average pullout load-slip curves for a fiber inclination angle: (a) 0 degrees, (b) 30 degrees and (c) 60 degrees. 
Cunha, V.M.C.F.; Barros, J.A.O.; Sena Cruz, J.M. (2010) "Pullout Behavior of Steel Fibers in Self-Compacting Concrete." Journal of Materials in Civil Engineering, 22(1), 1-9.

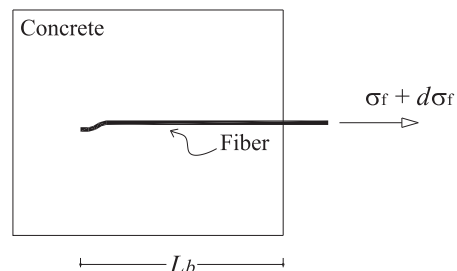

(a)

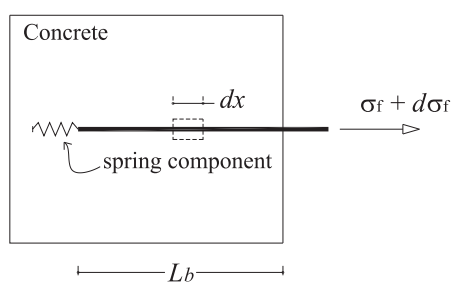

(b)

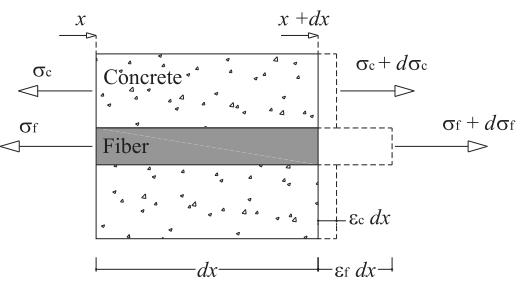

(c)

FIG. 4. Axisymmetric pullout model: (a) general problem, (b) simplified model (c) equilibrium of an infinitesimal fiber free-body. 
Cunha, V.M.C.F.; Barros, J.A.O.; Sena Cruz, J.M. (2010) "Pullout Behavior of Steel Fibers in Self-Compacting Concrete." Journal of Materials in Civil Engineering, 22(1), 1-9.

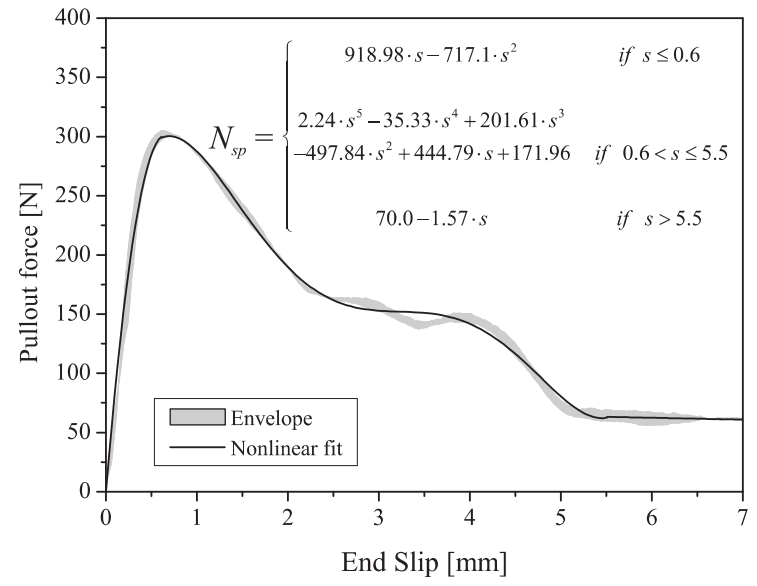

FIG. 5. Analytical simulation of the hook mechanical contribution. 
Cunha, V.M.C.F.; Barros, J.A.O.; Sena Cruz, J.M. (2010) "Pullout Behavior of Steel Fibers in Self-Compacting Concrete." Journal of Materials in Civil Engineering, 22(1), 1-9.
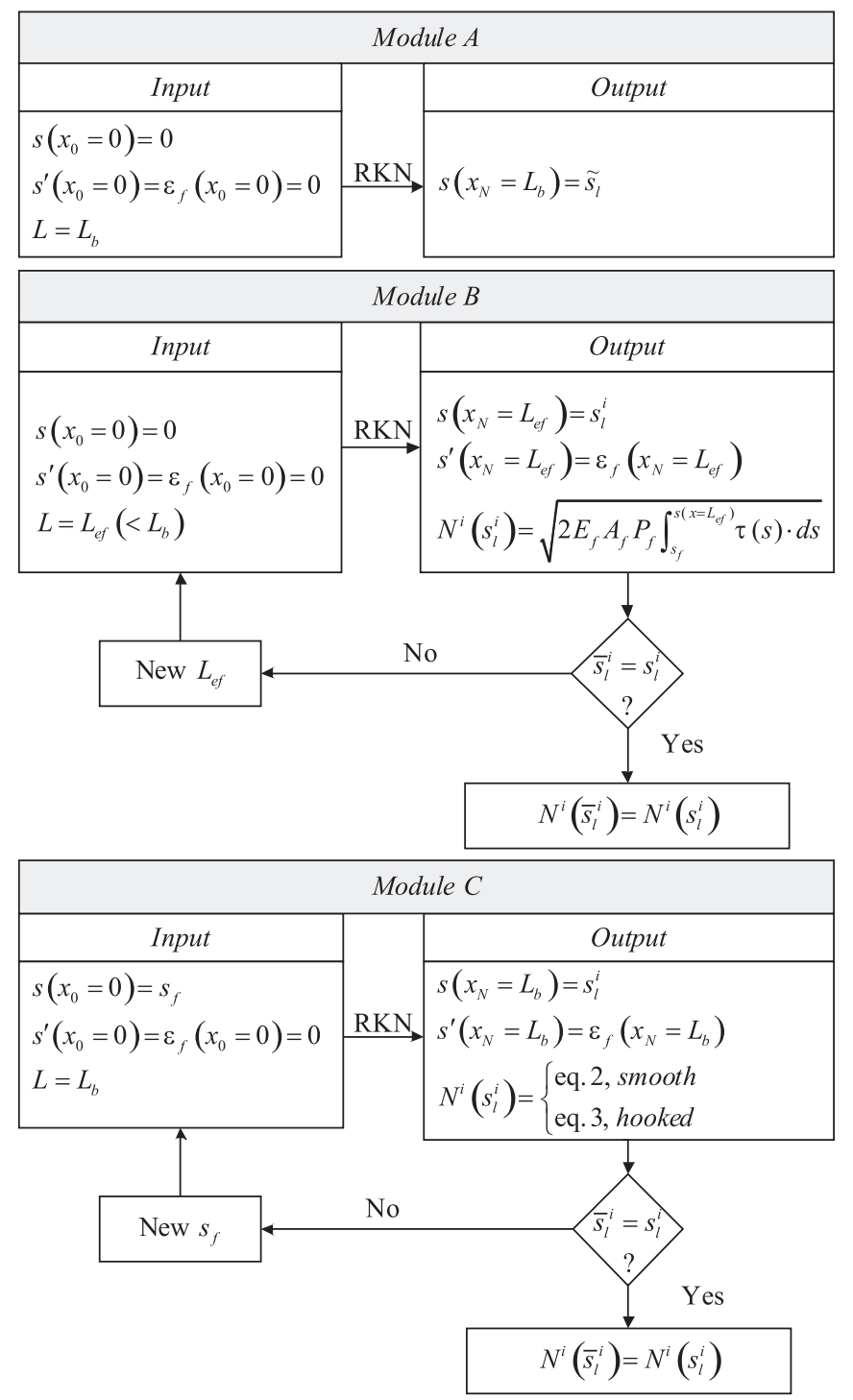

FIG. 6. Modules A, B and C of the algorithm. 
Cunha, V.M.C.F.; Barros, J.A.O.; Sena Cruz, J.M. (2010) "Pullout Behavior of Steel Fibers in Self-Compacting Concrete." Journal of Materials in Civil Engineering, 22(1), 1-9.
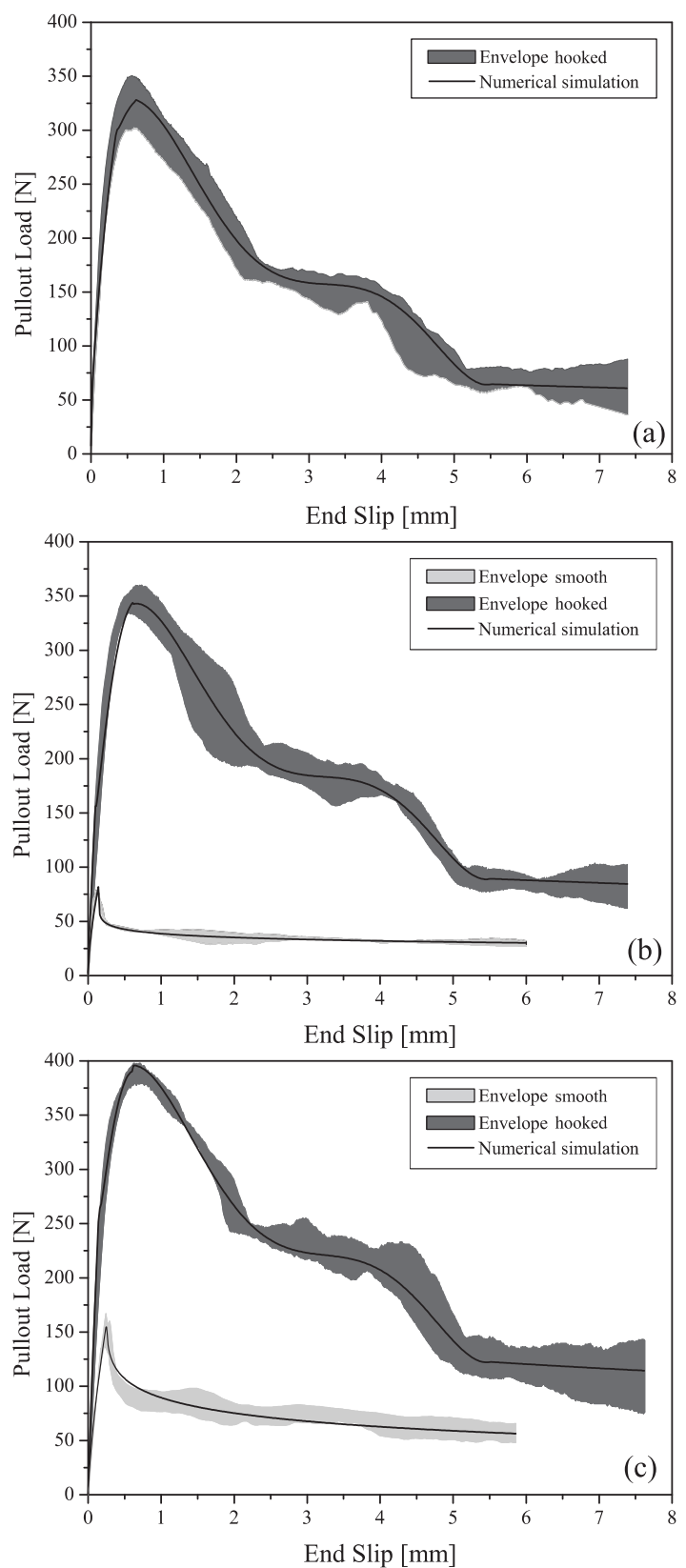

FIG. 7. Pullout load-slip numerical simulation for the series with an embedded length of: (a) $10 \mathrm{~mm}$, (b) $20 \mathrm{~mm}$ and (c) $30 \mathrm{~mm}$. 